\title{
Opinion of Women Regarding Prohibition and Criminalization of Female Genital Cutting
}

\author{
Hagar A. Ahmed ${ }^{1}$, Inas K. Kassem ${ }^{2}$, Soheir A. Hassan ${ }^{3}$ \\ ${ }^{1}$ Teacher in Shebin El-Kom Nursing School, ${ }^{2}$ Professor of maternal and new born health nursing, \\ ${ }^{3}$ Lecturer of maternal and new born the health nursing, Faculty of Nursing, Menoufia University.
}

\begin{abstract}
Background Female genital mutilation refers to a variety of operation on the private parts of women and young girls that involves partial or total removal of the external genitalia. This practice cause, injury to female genital organs for cultural or non-therapeutic reason (WHO, 2010). The aim of the current study is to identify the opinion of women regarding prohibition and criminalization of female genital cutting (FGC). Design: A descriptive study design was used. The sample a number of 240 women were selected from two medical health centers located in Menoufia governorate. Tools of this study included a structured interview questionnaire. The results of the present study revealed that more than two third $(66.9 \%)$ of the study sample were against prohibition and criminalization of female circumcision and only $33.1 \%$ agreed that it should be prohibited and criminalized. It was concluded that the majority of the study sample didn't agree with the law that prohibited and criminalized female genital cutting and intended to circumcise their daughters. Recommendation, it is recommended that Outreach program must be designed to reach rural and remote areas residents to correct their concepts about female genital cutting
\end{abstract}

Key words: Female Genital Cutting, criminalization.

\section{Introduction}

Female genital mutilation/cutting (FGM/C) is defined by the World Health Organization (WHO) and United Nations agencies as a procedure that involves the "partial or total removal of the external female genitalia or other injury to the female genital organs for non-medical reasons" (WHO, 2008). It is estimated that up to 140 million girls and women have undergone FGM/C worldwide. In the 29 countries in Africa and the Middle East where the practice is concentrated, it is estimated that at least 120 million girls and women have experienced female genital cutting (Unicef, 2013).

Female genital mutilation is widely recognized as a harmful practice and a human rights violation. It reflects deeprooted gender inequalities and has devastating short-term and longterm impacts on the health and lives of women and girls (WHO, 2012). It functions as a self-enforcing social convention and acts as a social norm - individuals and families uphold the practice because they believe that their group or society expects them to do so. Otherwise, they suffer social sanctions (Unicef, 2013).

FGC is usually performed on girls at an age that ranges between four and ten. Sometimes it is performed on infants or at the age of marriage. At other times, circumcised girls seek the removal of what they think are remnants of a former circumcision operation before and after marriage. It is usually performed under insanitary conditions, by nonmedical traditional practitioners, using non sterile instruments and without use of anesthesia. In many instances it results in immediate \& delayed serious complications. Thus the health and even the life of its victims are compromised (Amnesty, 2009).

There is no clear cut understanding of where or why FGC came into existence. It predates both Islam and Christianity. One of the most common explanations for continuing it is local customs and traditions. It is strange that women themselves are sometimes unwilling to give up the practice as they see it a longstanding tradition passed on from generation to generation (Obi Sn, 2006). 


\section{Opinion of Women Regarding Prohibition and Criminalization of Female Genital}

Cutting

Currently there is a strong universal opposition to FGC which is based on many dimensions. Firstly the procedure is considered an infringement on the physical and psychosexual integrity of girls and women, secondly it is a form of violence against them and thirdly it violates their human rights (Hopikins, 2007).

Over the last several decades, efforts to address FGM/C have intensified with the support of many partners, including governments, international institutions, non-governmental organizations, religious and other civil society groups, and local communities. These efforts have contributed to and benefitted from an evolving understanding of the practice and of the social dynamics that lead to its abandonment. New insights into FGM/C are informing the design of policies and programmes both in countries where it has been practised for generations and in areas where it is relatively new and associated with immigration (Unicef, 2013).

The nurses have important role to stop these practices by teaching women about the effect of female genital mutilation on women health and support girls who suffer from the dire consequences of the procedure (Royal college of nursing 2014). Also the nurse plays an important role to woman as supportive person because she has many roles if done effectively she become good support woman as educator, counselor and care giver about female genital cutting (WHO 2008).

In Egypt the Ministry of Health and Population has announced the launch of a national plan against female genital mutilation (2020-2016). In order to reduce the practice of female circumcision rates amid new generations at the national level, and through the support of social, cultural and political climate to enable the Egyptian family of the decision not to do female genital mutilation, and reduce the prevalence of the practice of female genital mutilation at the national level (Almasryalyoum, 2015).

\section{Purpose}

The aim of this study is to explore the opinion of women regarding prohibition and criminalization of female genital cutting

\section{Research question:}

- Do women endorse the laws of prohibition, and criminalization of female genital cutting?

- Will they abide these laws?

\section{Methods}

Research design: A descriptive study was used to the present study participants: total number 240women who attended maternal and child health centers for child vaccination was included.

Setting: The study was conducted in two Maternal and Child Health Centers (Shebin Elkom health center and Meleeg health center in Menoufia governorate) .

\section{Data collection tools}

A structured interview questionnaire was used for data collection

\section{Part I:}

Social characteristics of mother such as: age, address, level of education, occupation, marital status.

\section{Part II:}

a. Women's knowledge about FGC such as definition, reasons, types of circumcision, practitioners of female genital cutting, nature of instruments used, anathesia that used and complications of Female genital mutilation.

b. Family profile such as family type number of daughters in the family and age of females who passed through genital mutilation.

\section{Part III:}

Opinion of women regarding prohibition and criminalization of female genital cutting and their intentions to stop it. It included question such as does circumcision prevents adultery? , is circumcision part from the teachings of 
religion?, does circumcision prevents adultery?

\section{Validity:}

The validity of the tools was ascertained by a group of three lectures from Faculty of Nursing Maternal and Newborn Health Nursing also two physician (obstetrics and gynecology department) from faculty of medicine who reviewed the instruments for face validity. Also they were asked to judge items for completeness and clarity of the sentences, the appropriateness of its content, the sequence of its items and accuracy of recording items. Suggestions were incorporated into the tool.

\section{Reliability:}

Test -retest reliability was applied by the researcher for testing the internal consistency of the instruments. It is the administration of the same instruments to the same participants under similar condition on two or more occasions scores from repeated testing were compared.

\section{Methods:}

A written permission was obtained from the vice dean of post graduate and research at faculty of Nursing, Menoufia University for the directors of the Maternal and child health centers in Shebin Elkom and Meleeg Health Centers

\section{Ethical consideration:}

An informed oral consent to participate in the current study was taken after the purpose of the study was explained to each women. The researcher informed each women that participation in the study was voluntary and she could withdraw from the study at any time .Each participant was personally interviewed, the aim of the study was explained. Confidentiality of the obtained personal data, as well as respect of participant's privacy was totally ensured.

\section{Pilot study}

A pilot study was conducted on 24 women to test the feasibility, clarity and applicability of the tool and estimate the time needed to collect the data from the whole sample. This sample was not included in the present study sample due to changes that were done in the tool based on the finding of the pilot study.

\section{Data collection procedure:}

\section{Preparatory phase:}

An extensive review of all data related to the study was done including electronic thesis and dissertation, available books, articles and periodicals. A review of related literature to formulate the knowledge basis relevant to the study area was also done.

\section{Implementation phase (data collection):}

Data collection started from January 2015 until end of June 2015. Data was collected from 9.00am. to $12.00 \mathrm{pm}$, for 4 dayslweek. Two days in Shebin Elkom Health Center and two days in Meleeg Health Center. All women were interviewed; if the participants were illiterate the researcher filled the instrument by herself. Meanwhile, educated women answered the questions by themselves. Then, the researcher reviewed every item in the presence of the women to ensure that no item was missed.

\section{Statistical design:}

The data collected were, categorized, tabulated, analyzed and presented in descriptive forms by using SPSS version 16.

The necessary tables were then prepared and statistical analysis included the arithmetic mean, standard deviation and chi-square test.

\section{Results}

Table (1): Shows the Social characteristics of the study sample. More than half of the study sample, their age were 30 years old, finished secondary school and urban residence $(51.6 \%, 52.5 \%$ and $50.8 \%$ respectively). Most of the study sample (78.8\%) was house wives. Approximately, 


\section{Opinion of Women Regarding Prohibition and Criminalization of Female Genital \\ Cutting}

all of them $(96.7 \%)$ were married and $(82.5 \%)$ married before age 20 . Near by half of them $(48.3 \%)$ had been married for more than 15 years.

Table (2): show that knowledge of study sample about parts removed. More than half $(55.4 \%)$ of the studied sample knew the parts to be removed .The majority (71.4\%) of studied sample pointed to clitoris. Approximately near to one third of studied sample $(21.8 \%)$ pointed to clitoris and labia minora. Surprisingly $4.5 \%$ of the studied sample pointed to the removal of all parts.

Table (3): show that information of the Study sample According to Information about Laws that Prohibit and Criminalize of FGC: Most of the studied sample (67.9\%) knew the laws that prohibit and criminalized FGC. Regarding the source of information about laws the majority of the studied sample (91.4\%) were informed by television. Two thirds of studied sample didn't agree with this law and more than one third of studied sample (39.2\%) reported that they will abide by this law, but more than two thirds will not abide by this law.

Table (4) showed that general opinion of the study sample towards FGC. It is observed that less than one half $(42.9 \%)$ agreed that FGC was one of religious beliefs. More than one third $(37.5 \%)$ stated that husbands prefered circumcised wife, It was also observed that more than half $(57.9 \%)$ of mothers disagreed with statements that FGC can harm girls. More than one third (38.8\%).agreed that FGC prevented adultery. It was observed that the majority $(65 \%)$ of the study sample disagreed that FGC could cause problems during pregnancy. Regarding the effect of FGC on marriage, it was found that more than one half $(58.3 \%)$ of studied women disagree that FGC affected marriage badly. It was also observed that more than one half $(58.3 \%)$ disagree that FGC had negative effects on psychological status of girls. It was observed of them that $67.1 \%$ and $48.8 \%$ disagreed that FGC helped in reproduction and prevented disease. Meanwhile $6.7 \%$ and $26.7 \%$ agreed that it could cause reproductive problems.

Fig 1 Shows information of the studied sample about the reasons for performing FGC, near half $(42.9 \%)$ of studied sample did FGC to comply with social habits. While more than one third $(38.3 \%)$ perform it as chastity of girl. Regarding to religious beliefs and marriage preparation reasons were found between $(11.2 \%$ and $7.5 \%$ respectively).

Fig 2 Shows prevalence of the studied study sample regarding subjection to FGC. It was clear t $95.4 \%$ had FGC only $4.6 \%$ had not FGC.

Table 1: Social characteris study sample:

\begin{tabular}{|l|c|c|}
\hline \multicolumn{1}{|c|}{ Characteristics } & $(\mathbf{n = 2 4 0})$ & \% \\
\hline Woman's age & 22 & 9.1 \\
$<20$ & 94 & 39.1 \\
$20-$ & 124 & 51.6 \\
30- & & 10.4 \\
\hline Woman's education & 25 & 10.4 \\
Illiterate & 25 & 52.5 \\
Read and write & 126 & 26.7 \\
Secondary or deploma & 64 & 21.2 \\
university & & 78.8 \\
\hline Woman's occupation & 51 & \\
Working & 189 & 50.8 \\
Not working & & 49.2 \\
\hline Residence & 122 & \\
Urban & 118 & 96.7 \\
Rural & & 3.3 \\
\hline Marital status & 232 & \\
Married & 8 & \\
Divorced & & \\
\hline Age at marriage & & \\
\hline
\end{tabular}


Opinion of Women Regarding Prohibition and Criminalization of Female Genital

Cutting

\begin{tabular}{|l|c|c|}
\hline$<20$ & 198 & 82.5 \\
$20-29$ & 37 & 14.1 \\
30 -or more & 10 & 3.3 \\
\hline Duration of marriage & 27 & 11.25 \\
$<5$ & 49 & 20.4 \\
$5-$ & 48 & 20 \\
$10-$ & 116 & 48.3 \\
$15-$ & \\
\hline
\end{tabular}

Table (2): Knowledge of Study Sample About Parts Removed:

\begin{tabular}{|l|c|c|}
\hline Characteristics & $(\mathrm{n}=240)$ & $\%$ \\
\hline Knowing parts to be removed in FGC & & \\
Yes & 133 & 55.4 \\
No & 107 & 44.6 \\
\hline In case of yes, The parts to be removed(n=133) & 95 & \\
Clitoris (type I) & 29 & 71.4 \\
Clitoris and labia minor a (Type II) & 2 & 21.8 \\
Labia minor a and stitching it with labia major a (Type III) & 1 & 1.5 \\
Total removal with cauterization (Type Iv). & 6 & 0.8 \\
All above & 4.5 \\
\hline
\end{tabular}

Table (3): Information of the study sample about Laws that Prohibit and Criminalize FGC:

\begin{tabular}{|l|c|c|}
\hline Variables & $(\mathrm{n}=240)$ & $\%$ \\
\hline Do you know punishment of law for FGC? & 163 & 67.9 \\
Yes & 77 & 32.1 \\
\hline No & & \\
If yes, the source is: & 149 & 91.4 \\
Television & 4 & 2.4 \\
Radio & 4 & 2.5 \\
Parents & 2 & 2.5 \\
Neighbors & & 1.2 \\
\hline Friends & 54 & 33.1 \\
Approving this law (n=163) & 109 & 66.9 \\
Yes & & \\
No & 94 & 39.2 \\
Will you abide by this law? & 146 & 60.8 \\
\hline No & & \\
\hline
\end{tabular}

Table (4): General opinion of the Study sample towards FGC:

\begin{tabular}{|l|c|c|}
\hline Variables & $(\mathrm{n}=240)$ & $\%$ \\
\hline FGC is one of religious education & 103 & 42.9 \\
Agree & 91 & 37.9 \\
Disagree & 46 & 19.2 \\
Don't know & & \\
Husbands prefer circumcised wives & 90 & 37.5 \\
Agree & 73 & 30.4 \\
Disagree & 77 & 32.1 \\
Don't know & & \\
\hline FGC may harm girls & 74 & 30.8 \\
Agree & 139 & 57.9 \\
Disagree & 27 & 11.2 \\
Don't know & & 38.8 \\
\hline FGC prevents adultery & 93 & 34.2 \\
Agree & 82 & 27.1 \\
Disagree & 65 & 10.8 \\
Don't know & & 65.0 \\
\hline FGC causes problems during pregnancy & 26 & 24.2 \\
Agree & 156 & 23.3 \\
Disagree & 58 & 58.3 \\
Don't know & & 18.3 \\
\hline FGC affects marriage opportunities badly & 56 & 140 \\
Agree & 44 & \\
Disagree & & \\
Don't know & & \\
\hline
\end{tabular}


Opinion of Women Regarding Prohibition and Criminalization of Female Genital Cutting

\begin{tabular}{|l|c|c|}
\hline FGC have negative effects on psychological state of girls & & \\
Agree & 50 & 20.8 \\
Disagree & 140 & 58.3 \\
Don't know & 50 & 20.8 \\
\hline FGC helps have children & 16 & 6.7 \\
Agree & 161 & 67.1 \\
Disagree & 63 & 26.2 \\
\hline Don't know & & \\
FGC prevents inflammation or diseases & 64 & 26.7 \\
Agree & 117 & 48.8 \\
Disagree & 59 & 24.6 \\
Don't know & & \\
\hline
\end{tabular}

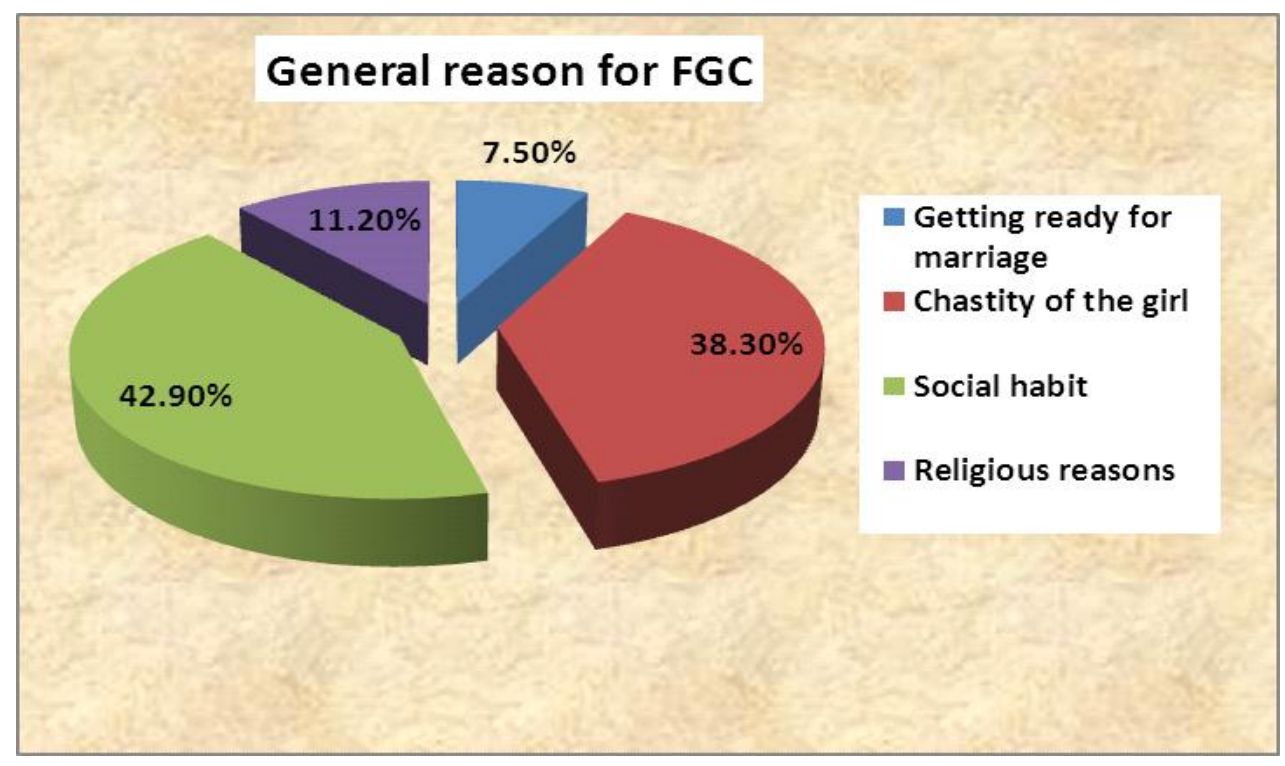

Fig 1: Information of the studied sample about the reasons for performing FGC

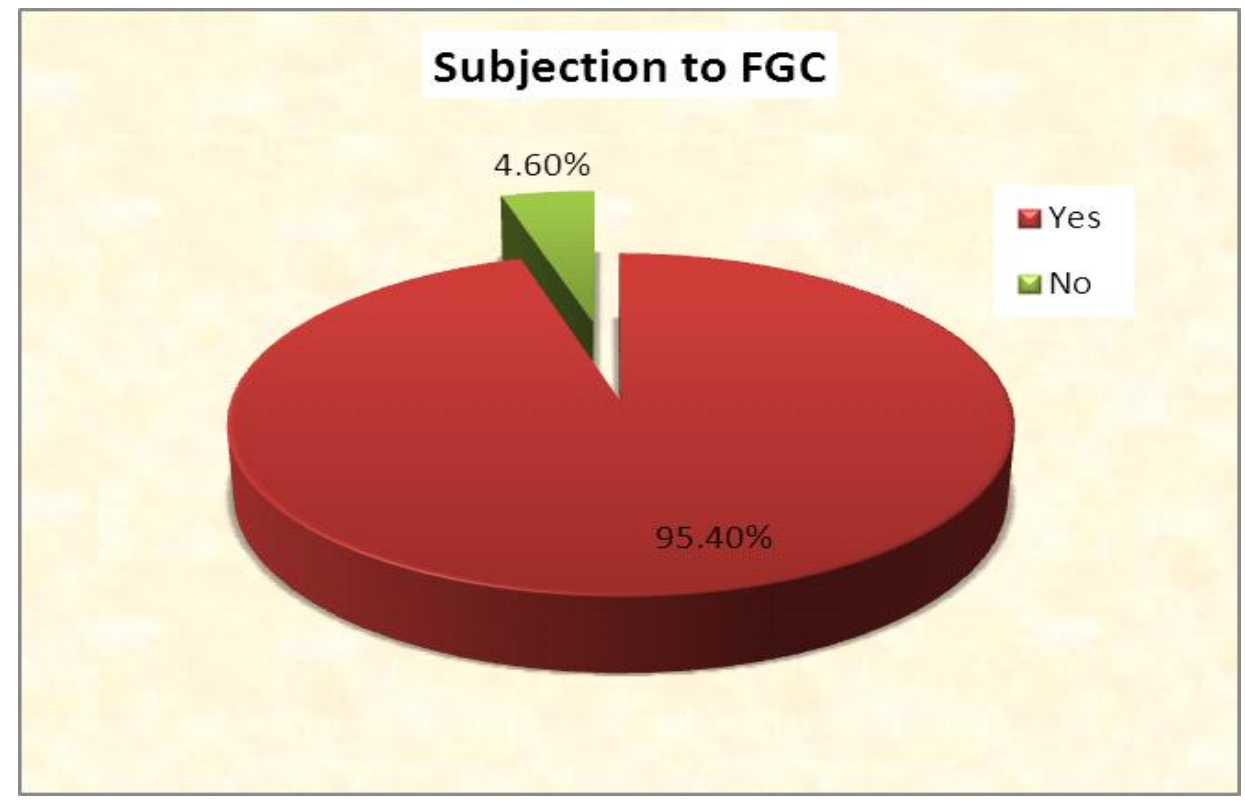

Fig 2: Prevalence of the Studied Sample Regarding Subjection to FGC. 


\section{Opinion of Women Regarding Prohibition and Criminalization of Female \\ Genital Cutting}

\section{Discussion}

The finding of the present study related to reasons for undertaking FGC revealed that the main reasons were complying with social habit, preserving chasity and adhering to religious rules. This result agreed with a study in USA by Nour (2008)" Female genital cutting a persisting practice". It was reported that the reasons for undertaking FGC included rites, preserving chastity, ensuring marriage ability, religion, hygiene, improving fertility, and enhancing sexual pleasure for men. This indicated how submissive the clients were in sex matters. They perceived themselves as sex objects that might satisfy husbands. The results obtained from the Demographic and Health Surveys in Egypt in 2014 showed that less than three quarters of ever-married women reported that circumcision was part of religious traditions in Egypt. The reasons provided to justify FGC were numerous and similar in almost all studies done in this domain and over the years.

Regarding to type of FGC the present study revealed that the majority of the study sample had type I \&II circumcision. This findings was supported by the finding of a study in Ain Shams University by Tag Eldin, et al.,( 2008) their study was about the prevalence of female genital cutting among Egyptian girls It was reported that the most common forms of FGC were type I (commonly referred to as clitoridectomy) and type II (commonly referred to as excision).

Regarding information about FGC, the present study showed that mass media was the primary source of information about law of FGC. So it was important that mass media must intensify their message about these laws because it is a powerful mean for transmission of information and could reach homes easily .This finding was consistent with the findings of EDHS which showed the effect of mass media as a primary source of information for peoples.

The results of the study revealed that the prevalence of FGC among the studied sample exceeded $95 \%$. This finding was close to the finding of Abdmotagaly (2010) in her study in Ain Shams University, "Assess the Factors Affecting the Persistence of Practice Female Genital Mutilation among Egyptian Females" she reported that $85.5 \%$ of her study sample was circumcised . Also, it was consistent with Naguib (2012) Study in Boston University his study about "The Effects of Social Interactions on Female Genital Mutilation: evidence from Egypt" who reported that $82 \%$ of his studied sample was circumcised, Above all, it was also reported by the ministry of family and population that the FGC is no longer practiced in some Egyptian governorates in upper Egypt. This show that Menoufia governorate behind other governorates in Egypt and more effort is needed to eradicate FGC there.

The result of the present study showed that approximately half of studied sample believed that FGM was a religious belief. This finding was in agreement with the study of Burkinafaso by Kormaker et al( 2011) "factors associated with female genital mutilation and its polisy implications", and study in Ethiopia by Bogale (2014) "Prevalence of Female Genital Mutilation and its Effect on Women's Health"it was mentioned that most of studied sample had FGM according to sunna circumcision.

Also it was observed in the present study that more than one third of studied sample reported that husband's prefered circumcised wife. This 


\section{Opinion of Women Regarding Prohibition and Criminalization of Female Genital Cutting}

finding was supported by Missalidis and Dcebre (2011) this study about Female genital mutilation, that reported two third of studied sample had the impression that the husband prefers his wife to be circumcised.

The present study showed that more than half of the studied sample believed that circumcision can't harm girls physically. These results were in agreement with a study in western Kenya by Christoffersen, (2010) study was about "Taming Tradition Medicalization Female Genital Practices". He reported more than half of studied sample believe that circumcision prevented nervousness that in girls and women, circumcision prevents pallor and made women's face beautiful

The present study showed that more than one third reported that FGC prevented adultery. These findings were supported by the results of EDHS (2014) which reported that more than one- third of married women considered it as methods of prevention adultery.

The present study showed that most of studied sample disagreed that FGC could cause problems during pregnancy. These findings were in agreement with the findings of study in Harvard University, by Obermeyer (2012). His study about" the consequences of female circumcision for health and sexuality An update on the evide" it was reported that approximately to half of circumcised studied sample complained from bacterial vaginosis and herpes simplex virus during pregnancy in comparison with lessthan one third of non circumcised studied sample

It was observed in the present study that more than half of studied sample reported that the FGC didn't affects marriage opportunities badly. These findings were supported by the findings of a study in Nyanza by Niue
(2011) His study was about "Medicalization of Female Genital Cutting among the Abagusil" .He reported that most of the studied sample believed that they were acting in the girl's best, as it will help them to marry and acquire status and respect in their community.

Most of studied sample in this study reported that FGM didn't affect on psychological status of girl badly. This results disagreed with the findings of a study in Netherlands by Vloeberghs et al., (2012) . The study was about coping and chronic psychosocial consequences of female genital mutilation, Ethnicity and Health it was mentioned that one sixth of girls suffered from post traumatic stress disorders (PTSD) and one third of them had symptoms related to depression and anxiety.

The present study revealed that most of studied sample disagreed that FGC could help in child birth. Accordingly these results consistent with the study of WHO (2009) the study was about female genital mutilation exposes women and babies to significant risk at child birth. It was reported approximately half of studied sample mentioned that FGM could cause particular dangers in child birth and neonatal problems because of obstructed or prolonged labour and could lead to fetal death.

\section{Conclusion}

The majority of women attending $\mathrm{MCH}$ in Shebin Elkom health center and Meleeg health center in Menoufia governorate didn't endorse the laws that prohibit and criminalize female genital circumcision. Because it's justification to comply to social habits, religious reasons and to reduce sexual desire. Also most them willn't abide by this law and because the decision makers of FGC returned to their 


\section{Opinion of Women Regarding Prohibition and Criminalization of Female \\ Genital Cutting}

husbands and they intend to circumcised their daughters.

\section{Recommendations}

- Based on the findings of the present study, the following recommendations are suggested:

- Integrate FGC topics in all training programs that are done in the $\mathrm{MCH}$ centers

- Activation the law that prohibits and criminalizes FGC.

\section{Reference}

Christofferssen- Deb., (2010): Taming tradition medicalization female genital practices in western Kenya, medical anthropology 14:402-418.

Elmotagally, H (2010): Assess the factors affecting the persistence of practice female genital mutilation among Egyptian females. Ain shames University Vol 40 no 1.

Karmaker B, Kan dala N, Chung D, Clarke A, (2011): factors associated with female genital mutilation in Burkina- faso and its polisy implications, 1186/1475-9276.

Naguib K, (2012): the effects of social interactions on female genital mutilation: evidence from Egypt Boston University, Department of economic, July.

Nour, N. M., (2008): Female genital cutting: a need reform. Obstetric Gvnecol; 101:1051-2.

Obermeyer, C (2012): the consequences of female circumcision for health and sexuality: An update on the evidence. 7 (5): 443-461.

Tag- Eldin M, Gadallah A, Al Tayeb M, Abdel- Aty M, Mansour E and Salem14. Prevalence of female Genital cutting among Egyptian Girls, Bulletin of the world health organization. Ain shams university, Cairo April 2008, vol 86, N (4)): 269-274.

Vloeberghs, E, Knipscheer, van derkwaak, A, (2012): coping and chronic psychosocial consequences of female genital mutilation in Netherlands, Ethnicity and Health pp. 677695.

WHO. Nursing Beyond the year 2009. Geneva: WHO, 2010; 5-12.

Niue, C, and Askew, I, (2011): Medicalization of female genital cutting among the Abagusil in Nyanza province, Kenya, frontiers in reproductive Health program, population council, pp 526-532

Missailidisk, Debre, (2011): Female genital mutilation in eastern Ethiopia, pp 137-138-101016/50140.

Bogale D, BMC public health (2014): 14:1076- 1471- 2458. 4-1076.

Dirie, M.A, Lindmark, G., (2010): The risk of medical complications after female circumcision. East African Medical Journal, Volume 69 Number 9:'Pages 479-482.

Egyptian Demographic and Health survey (EDHS), 2014. 9-12. 